\section{TRULY UNIQUE IMPLANTS}

Nobel Biocare's pioneering research and development have enabled clinicians to tackle complex rehabilitations of the edentulous maxilla and the mandible with ease, thanks to the truly unique All-on-4 system.

Compatible with NobelGuide, the All-on-4 system reduces patient chair time and simplifies the entire dental implant procedure. The system involves the placement of two straight anterior implants and two angulated posterior implants to hold a full arch restoration. In many cases your patient can leave the surgery with a functional, aesthetically pleasing set of teeth after just one treatment session.

The All-on-4 system is also a highly cost-effective solution, opening up the possibility of dental implant treatment to a wider patient base and to potentially increase case acceptance and practice turn over.

Your patients will also find the Allon-4 system noticeably less traumatic than many other systems, as it avoids the need to completely rehabilitate the upper and lower jaw, and recovery times is much faster.

Reader response number 53

\section{COMPACT WATER FLOSSER}

Designed specifically for the UK market, the Nano Water Flosser from Waterpik is smaller and more compact than the original Waterpik Water Flosser and is the first Water Flosser designed to power from a shaver socket.

The Nano Water Flosser is ideal for cleaning hard to reach areas as it works interdentally and subgingivally. It is packed with time saving and userfriendly features such as the space saving design, allowing for easy storage; three pressure settings so that patients can adjust it to suit their level of sensitivity; and two different tips: the Classic Jet Tip and the Plaque Seeker Tip for additional plaque removal in hard to reach areas.

\section{SUPERIOR CRAFTMANSHIP}

Does your dental laboratory provide a flexible service with quick turnaround times? Does it have friendly, knowledgeable staff and a personal point of contact? Does it deliver restorations safely in their own presentation boxes?

CosTech Elite is a laboratory that understands the pressure placed on practitioners to provide reliable, aesthetically pleasing restorations in a short amount of time.

As a dental practitioner, you will know how patients are increasingly demanding that they get the most
For patients who want effective plaque biofilm removal and reduced gingival bleeding, the Waterpik Nano Water Flosser is the ideal solution.

Reader response number 54

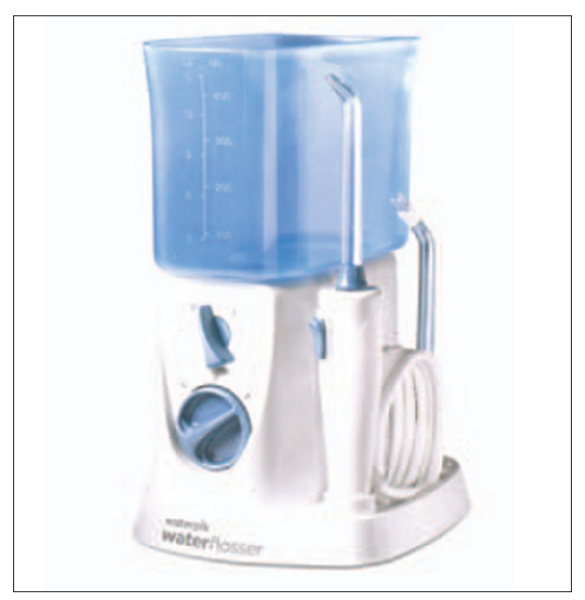

for their money. As a vital part of your team, your laboratory must also respond to their requests.

The team at CosTech Elite strives to ensure consistent quality through its expert group of GDC-registered Elite technicians, who pride themselves on providing bespoke solutions and superior craftsmanship, no matter how unique or challenging the requirements.

The laboratory's high-end Elite7 express service also guarantees a seven-day turnaround on restorations with a money back guarantee if your laboratory work is not received on time. Reader response number 55

\section{CANAL CONTROL WITH REWARDS}

The Wave0ne from Dentsply is a new endodontic system that uses reciprocating technology. This means that it will only shape the canal when pressure is applied, giving the practitioner a feeling of complete control. WaveOne also simplifies the procedure, requiring just one premium quality NiTi instrument per root canal procedure in most cases. The perfect solution to those wishing to switch from hand files to a rotary based system.

Dentsply uses an innovative thermal treatment process to create the M-Wire NiTi material. Its resulting characteristics provide overall flexibility and greater resistance to cyclic fatigue, the leading cause of file separation. The geometry of the WaveOne files and the WaveOne Dentsply M-Wire Nickel-Titanium technology are the main reasons for the superior performance of the WaveOne file compared to standard NiTi files.

Dentsply also offer Dentsply Rewards, where dental practices receive rewards for ordering products through the Dentsply Rewards website, which can then be spent on products to suit your practice.

Reader response number 56

\section{PERSONALISED EQUIPMENT} SERVICES

Being fully familiar with all your practice's equipment and special requirements, Henry Schein Minerva's manufacturer-trained technicians can offer the support you need by providing maintenance certification for your dental equipment. To ensure optimal performance of all your capital equipment, digital imaging, laser and CADCAM solutions, Henry Schein Minerva can deliver a full care and maintenance programme combined with a personalised, local service. They also have new service contracts available for all your KaVo equipment.

As the UK's leading provider of insurgery dental equipment services, Henry Schein Minerva take the time to install and fully train you on your new equipment so you feel confident in daily practice.

Reader response number 57 